\title{
The Use of SEM and Light Microscopy for the Characterization of Hypericum foliosum Aerial Part as a Medicinal Plant
}

\author{
R. Serrano, P. Ferreira, E. T. Gomes, and O. Silva
}

iMed-UL/CECF, Faculty of Pharmacy, University of Lisbon, Av. Prof. Gama Pinto, 1649-003 Lisbon, Portugal

The first step in quality control of herbal drugs is ensuring the correct identification of the plant intended for use. The required analytical procedures (macroscopic characterization of the entire or fragmentized material, microscopic characterization after pulverization of the plant material and chemical characterization), are usually described on quality monographs reported in authoritarian texts such as the European 6th Pharmacopoeia [1]. Further information related to the name of the each herbal drug, the herbal drug definition, purity tests and assay are also provided.

Hereby, we present the results of the application of scanning electron microscopy (SEM) and light microscopy (LM) to the characterization of Hypericum foliosum Aiton (Clusiaceae/Guttiferae) dried flowering aerial part, thus establishing the botanical criteria essential for the identification of this plant material used on the manufacture of herbal medicines and other industrial products.

H. foliosum is an Azorean endemism classified under section Androsaemum (Duh.) Godron [2], locally know as "Malfurada", "Furalha" or "Milfurada" and it is used in traditional medicine for the treatment of external wound ulcer. Additionally, H. foliosum is referred due to its immediate economic value as a direct gene pool available for plant breeding [3]. The chemical composition of the essential oil obtained by inflorescences hydro-distillation is already established [4] and a new acylphloroglucinol derivative with antiStaphylococcus aureus activity was identified on the aerial parts [5].

In our study, dried fragmentized stems, leaves, flowers and powdered flowering aerial parts were analysed. Results showed that the most useful characters for identification were: a) the stem transversal section with a thick layer of cork cells, cellular layers of laminar collenchyma interposed by parenchyma cells, essential oil ducts dispersed in the cortex parenchyma (Fig.1) and amyliferous medullar parenchyma; b) the presence of round, translucent essential oil ducts in the dorsiventral surface of the leaf (Fig.2); c) the leaf bifacial mesophyll with two cellular layers at the palisade parenchyma level and the presence of essential oil ducts surrounded by four to seven gland cells on both palisade and spongy parenchyma (Fig.3); d) the 
flowers with epidermal petal cells of slightly undulated form and thin walls (Fig.4) and anthers with juxtaposed and sinuous epidermal cells containing a grooved cuticle.

Analysis of the greenish-yellow powdered material reveals, as the most frequent elements: fragments with cork cells from the stem; fragments of the lower surface of the leaves with sinuous walls and more frequent paracytic, sometimes anomocytic, stomata; fragments of anthers and numerous pollen grains with an obovate form and a reticulate exine (Fig.5).

The here presented macroscopic and microscopic characters of the whole, fragmentized and powdered $H$. foliosum dried aerial part should be regarded as fundamental and included in the Identification Part of a future pharmacopoeial monograph on this medicinal plant.

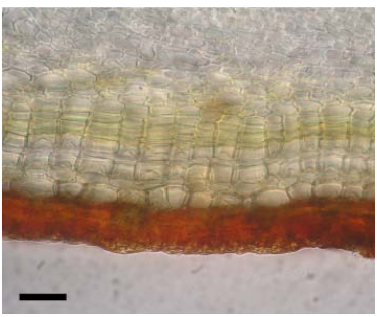

Fig.1. Stem transversal section detail Scale bar $=50 \mu \mathrm{m}$

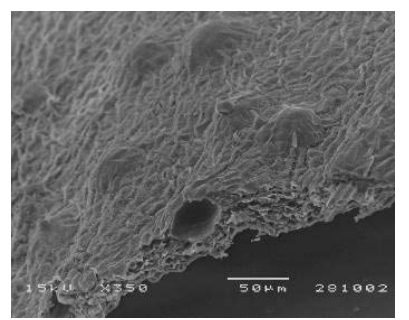

Fig.2. Leaf dorsiventral surface with oil ducts

Scale bar $=50 \mathrm{um}$

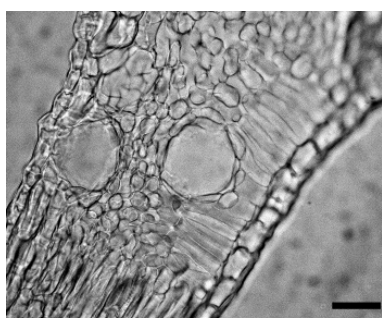

Fig.3. Leaf bifacial mesophyll transversal section Scale bar $=50 \mu \mathrm{m}$

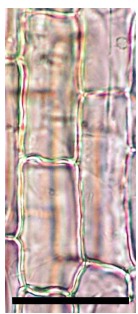

Fig.4. Epidermal petal cells detail Scale bar $=50 \mu \mathrm{m}$

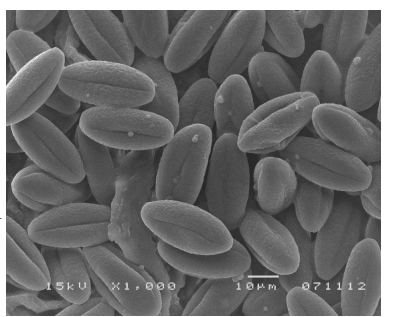

Fig.5. Pollen grains with obovate form and reticulate exine Scale bar $=10 \mu \mathrm{m}$

\section{References}

[1] European Pharmacopoeia, 6th ed., Council of Europe, Strasbourg, 2007.

[2] A. Franco, Nova Flora de Portugal, Sociedade Astória, Lisboa, 1984, vol. II, 449.

[3] L. Caixinhas et al., Portugal: Country Report to the FAO International Technical Conference on Plant Genetic Resources (Leipzig, 1996), Ministry of Agriculture, Oeiras, 1995, p. 17.

[4] P. A. G. Santos et al., Flavour Frag. J. 14 (1999) 283.

[5] S. Gibbons et al., Phytochemistry, 66 (2005) 1472.

[6] This work was supported by "Laboratórios Medinfar S.A.". 